www.mdpi.com/journal/marinedrugs

Article

\title{
New Prenylxanthones from the Deep-Sea Derived Fungus Emericella sp. SCSIO 05240
}

\section{Mangaladoss Fredimoses $^{\dagger}$, Xuefeng Zhou ${ }^{\dagger}$, Xiuping Lin, Xinpeng Tian, Wen Ai, Junfeng Wang, Shengrong Liao, Juan Liu, Bin Yang, Xianwen Yang and Yonghong Liu *}

Key Laboratory of Tropical Marine Bio-resources and Ecology, Guangdong Key Laboratory of Marine Materia Medica, RNAM Center for Marine Microbiology, South China Sea Institute of Oceanology, Chinese Academy of Sciences, Guangzhou 510301, China; E-Mails: moses10c@gmail.com (M.F.); xfzhou@scsio.ac.cn (X.Z.); xiupinglin@hotmail.com (X.L.); xinpengtian@scsio.ac.cn (X.T.); aiwen747@gmail.com (W.A.); Junfeng1982a@163.com (J.W.); 1jrss@126.com (S.L.); ljuan2010@qq.com (J.L.); bingo525@163.com (B.Y.); xwyang@scsio.ac.cn (X.Y.)

$\dagger$ These authors contributed equally to this work.

* Author to whom correspondence should be addressed; E-Mail: yonghongliu@scsio.ac.cn; Tel./Fax: +86-20-8902-3244.

Received: 1 April 2014; in revised form: 3 May 2014 / Accepted: 5 May 2014 /

Published: 28 May 2014

\begin{abstract}
Four new prenylxanthones, emerixanthones A-D (1-4), together with six known analogues (5-10), were isolated from the culture of the deep-sea sediment derived fungus Emericella sp. SCSIO 05240, which was identified on the basis of morphology and ITS sequence analysis. The newstructures were determined by NMR $\left({ }^{1} \mathrm{H},{ }^{13} \mathrm{C}\right.$ NMR, HSQC, $\mathrm{HMBC}$, and ${ }^{1} \mathrm{H}-{ }^{1} \mathrm{H}$ COSY), MS, CD, and optical rotation analysis. The absolute configuration of prenylxanthone skeleton was also confirmed by the X-ray crystallographic analysis. Compounds 1and $\mathbf{3}$ showed weak antibacterial activities, and $\mathbf{4}$ displayed mild antifungal activities against agricultural pathogens.
\end{abstract}

Keywords: prenylxanthone; Emericella; deep-sea; fungus

\section{Introduction}

Naturally occurringxanthones, dibenzo- $\gamma$-pyrone derivatives produced by higher plants, lichens, and fungi, contain different substituents on the two benzene rings, thus resulting in large structural 
diversity [1,2]. These substituents are strongly dependent on their biosynthetic origins and modification reactions [3]. Prenylxanthones, an important subgroup of naturally occurring xanthones, exhibit diverse biological and pharmaceutical activities, because of their specific substitution patterns [4].In many conditions, activities are associated with prenylation of the xanthone skeleton [5].Various biological and pharmacological activities, such as antibacterial, antifungal, anti-inflammatory, antioxidant, and antitumor, have been reported for prenylxanthones, which make these compounds attractive for pharmaceutical applications [6].

Marine fungi are known to be a prolific source of biologically active natural products which might be useful for drug discovery [7]. As a special ecosystem, marine sediment provides an abundant of fungal resources, which yielded various secondary metabolites with novel structures and interesting biological activities [8]. The genus Emericella fungi could produce a remarkable diversity of secondary metabolites, such as indole alkaloids, prenylated polyketides, benzophenones, and xanthones, with interesting biological properties thus representing potential leads for the developing of new pharmaceutical agents [9,10]. As part of our research program to discover new natural products from marine deep-sea sediment fungi from South China Sea, we have isolated four new (1-4) and six known (5-10) prenylxanthones, from the culture of a deep-sea sediment derived fungus Emericella sp. SCSIO 05240.

\section{Results and Discussion}

\subsection{Identification of the Fungus Strain}

A fungal isolate from deep-sea sediment $(3258 \mathrm{~m})$ of the South China Sea displayed activity against bacteria and fungi in our previous screening tests. The cultural and morphological properties suggested that the isolate, termed SCSIO 05240, was a strain of Emericella (Figure 1a-d). Abundant conidiophores and cleistothecia occurred on PDA medium. Conidial heads were mostly short cylindrical. Vesicles were hemispherical and biseriate. Metulae were smoothing walled and cylindrical. Phialides were smooth walled and flask shaped, approximately equal in length to those of metulae. Conidia were olive green and globose to subglobose when mature, and spiny (Figure 1b,c). Cleistothecia were spherical after mature, and were typically surrounded by thickened large spherical envelop cells (Figure 1d).

Figure 1. Colony appearance and micromorphology of strain SCSIO 05240. (a) Colony appearance after 7 days at $25{ }^{\circ} \mathrm{C}$ (PDA); (b) Conidiophores under SEM; (c) Conidia under SEM; (d) Cleistothecia as seening using SEM. Bars: $15 \mu \mathrm{M}$ (b), $5 \mu \mathrm{M}$ (c), and $50 \mu \mathrm{M}$ (d).
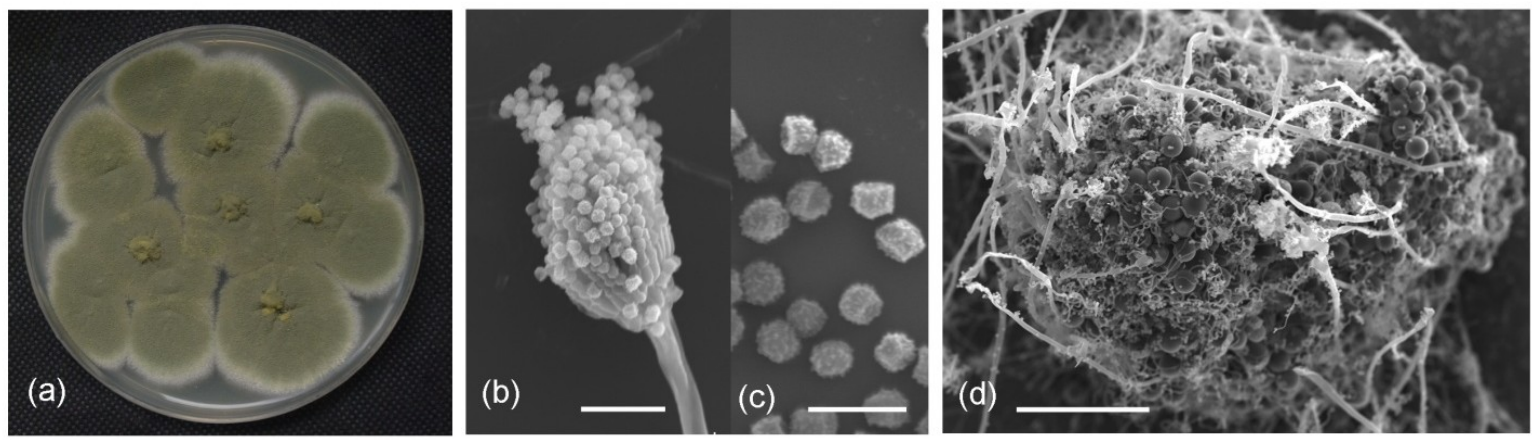
ITS1-5.8S-ITS2 sequence region (507 basepairs (bp), accession number KJ614489) of strain SCSIO 05240 was obtained and was found to be most similar to those of E.qinqixianii ML514, E. variecolor IFM 42010, and E. appendiculata IFM 54232, with sequence identity of $99 \%$. A phylogenetic tree was constructed, using the neighbor-joining method based on similarity of a 506-bp consensus length of ITS1-5.8S-ITS2 sequence (Figure 2), and confirmed that strain SCSIO 05240 grouped most closely with E. variecolor IFM 42010. The ITS region sequence identity confirmed that strain SCSIO 05240 belonged to genus Emericella, and was designated as Emericella sp. SCSIO 05240.

Figure 2. Neighbor-joining tree based on sequences of ITS region, showing phylogenetic relationships between Emericella sp. SCSIO 05240 and related Emericella species. Numbers at nodes indicate bootstrap values from 1000 replicates. GenBank accession numbers are given in parentheses. Bar, $0.2 \%$ sequence divergence.

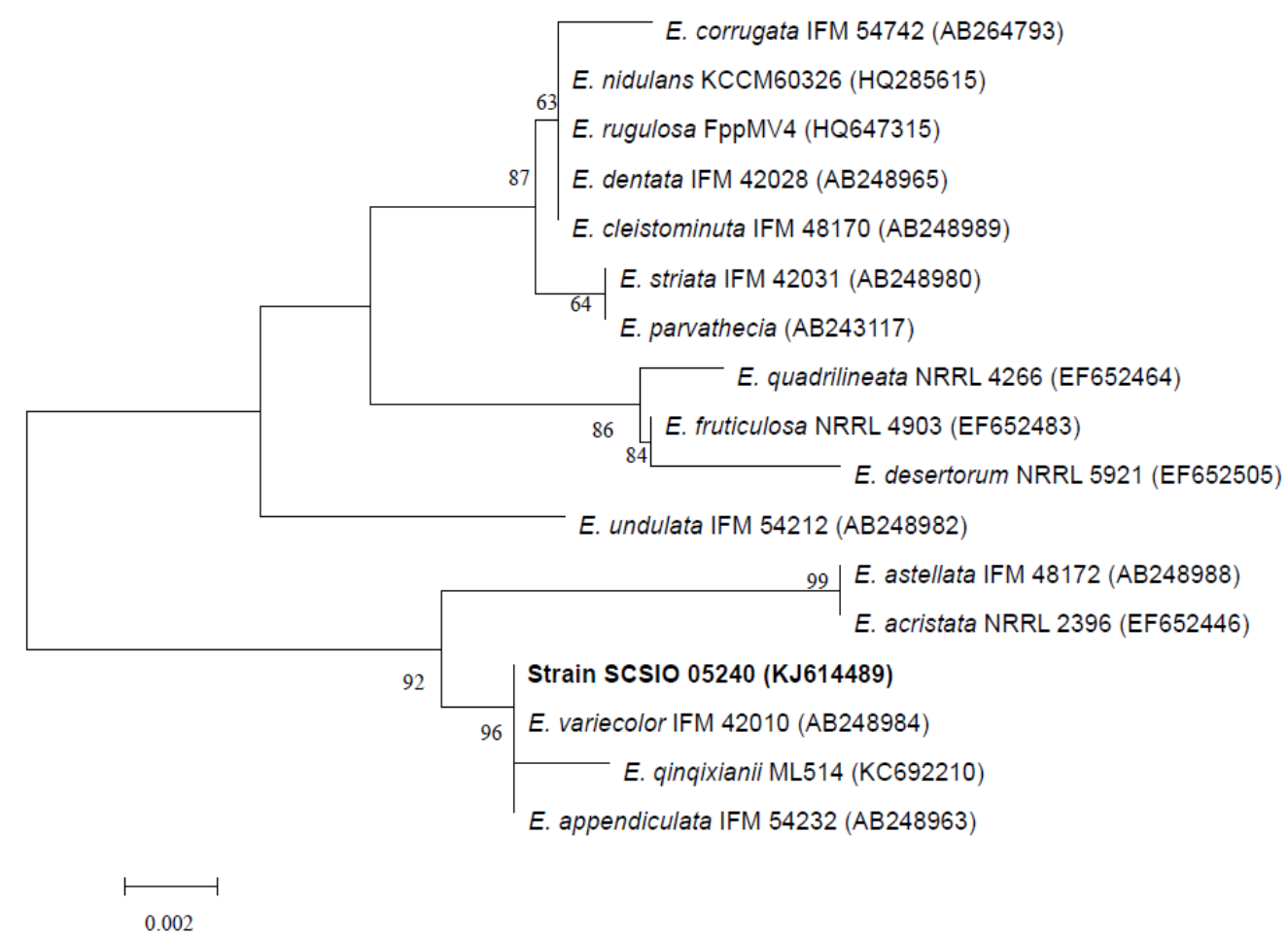

\subsection{Structure Elucidation}

Four new prenylxanthones, emerixanthones A-D (1-4), together with six known analogues (5-10), were isolated and purified from the cultures of SCSIO 05240. Six known prenylxanthones were identified as shamixanthone (5) [11], tajixanthone hydrate (6) [11], ruguloxanthone A (7) [12], ruguloxanthone $\mathrm{B}$ (8) [12], tajixanthone (9) [13], and tajixanthone methonate (10) [11], by comparison with their ${ }^{1} \mathrm{H}$ and ${ }^{13} \mathrm{C}$ NMR with those reported (Figure 3). In order to confirm the absolute configuration of prenylxanthones skeleton, the X-ray crystallographic analysis of ruguloxanthone B (8) was carried out (Figure 4). It is the first X-ray crystallographic analysis of the prenylxanthones derivatives. 
Figure 3. Chemical structures of compounds 1-10.<smiles>C=C(C)[C@H]1COc2c(C)cc3oc4c(C)ccc(O)c4c(=O)c3c2[C@@H]1O</smiles>

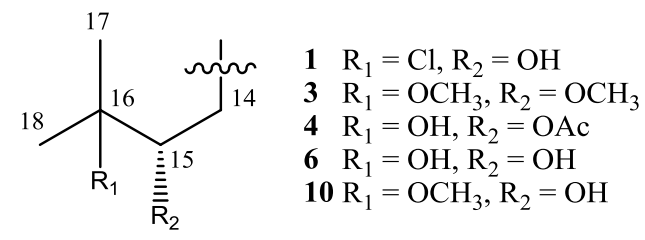<smiles>C=C(C)[C@@H](O)CN(C)CC</smiles><smiles>CCC(C)(C)C=O</smiles><smiles>CC(C)C(=O)CN(C)C</smiles><smiles>CN(C)C[C@H]1[C@H](O)C1(C)C</smiles>

Figure 4. X-ray structure of compound 8.

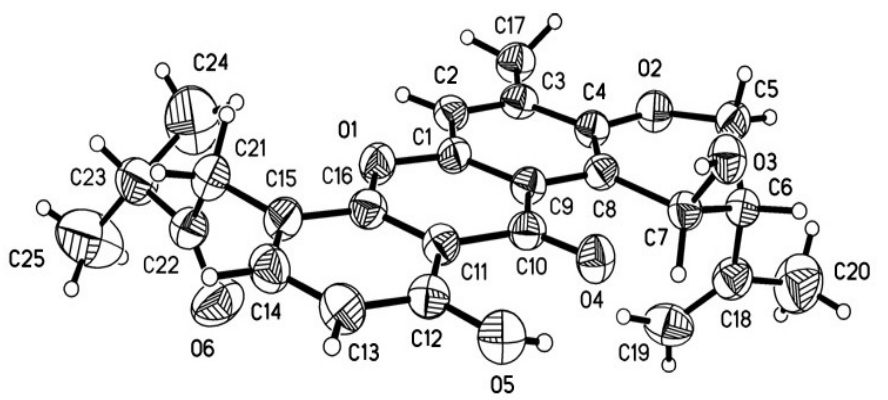

Compound 1 was obtained as yellow needle crystals and was assigned the molecular formula $\mathrm{C}_{25} \mathrm{H}_{27} \mathrm{ClO}_{6}$, as deduced from HRESIMS data $\left(\mathrm{m} / z 459.1569[\mathrm{M}+\mathrm{H}]^{+}\right.$, calcd for 459.1574$)$, indicating 12 degrees of unsaturations. The IR spectrum showed the presence of hydroxyl $3394(\mathrm{OH}), 2978$, 2916, and aromatic ketone 1639 and $1573(\mathrm{C}=\mathrm{O}), 1473,1431,1354,1292,1242,1049$ and 1018 (C-O-C), 856, and $821 \mathrm{~cm}^{-1}$. The ${ }^{1} \mathrm{H}$ and ${ }^{13} \mathrm{C}$ NMR spectra (Tables 1 and 2) and DEPT experiments suggested that the presence of 25 carbon signals, which were attributable to four methyls, three methylenes, six methines (including aromatic and chlorinated carbons), and nonprotonated (including one ketone carbonyl) carbons. The ${ }^{1} \mathrm{H}$ NMR spectroscopic data has showed resonances for three aromatic protons, with two $\left(\delta_{\mathrm{H}} 6.78, \mathrm{H}-2\right.$ and $\left.\delta_{\mathrm{H}} 7.55, \mathrm{H}-3\right)$ exhibiting ortho coupling $(J=8.5 \mathrm{~Hz})$ and the third $\left(\delta_{\mathrm{H}} 7.22, \mathrm{H}-5\right)$ appearing as a singlet. The aromatic methyl substituent $\left(\delta_{\mathrm{H}} 2.35, \mathrm{~s}, \mathrm{H}-24\right)$ was connected to position C-6, as supported by HMBC correlations of $\mathrm{CH}_{3}-24$ to C-5, C-6 and C-7. A chelated hydroxyl resonance at $\delta_{\mathrm{H}} 12.63$ was assigned to the aromatic carbon atom $\mathrm{C}-1$, as confirmed by HMBC correlations from $\mathrm{OH}-1$ to $\mathrm{C}-1$ and $\mathrm{C}-2$. The $\mathrm{OCHCHCH}_{2} \mathrm{O}$ spin system, corresponding to the $\mathrm{C}-19 / \mathrm{C}-20 / \mathrm{C}-25$ unit of 1 , was consistent with a dihydropyran ring fused to an aromatic ring at the position of $\mathrm{C}-7$ and $\mathrm{C}-8$, which was also confirmed by the $\mathrm{HMBC}$ and ${ }^{1} \mathrm{H}-{ }^{1} \mathrm{H}$ COSY correlations showed in Figure 5. The two terminal olefinic proton signals, together with a methyl singlet at $\delta_{\mathrm{H}} 1.84(3 \mathrm{H}, \mathrm{s}, \mathrm{H}-23)$, revealed that an isopropenyl moiety was connecting to the pyran ring at C-20 and was confirmed by $\mathrm{HMBC}$ correlation of $\mathrm{H}_{3}-23$ and $\mathrm{H}_{2}-22$ to $\mathrm{C}-20$. These data 
indicated the same prenylxanthones skeleton as the known derivative ruguloxanthone $\mathrm{B}(\mathbf{8})$, whose absolute configuration has been confirmed by X-ray.

Table 1. ${ }^{1} \mathrm{H}$ NMR spectroscopic data of compounds $\mathbf{1}-\mathbf{4}\left(\delta_{\mathrm{H}}\right.$, mult, $\left.J_{\mathrm{H}}, 500 \mathrm{MHz}, \mathrm{CDCl}_{3}\right)$.

\begin{tabular}{ccccc}
\hline No. & $\mathbf{1}$ & $\mathbf{2}$ & $\mathbf{3}$ & $\mathbf{4}$ \\
\hline 2 & $6.78, \mathrm{~d}, 8.5$ & $6.76, \mathrm{~d}, 8.5$ & $6.78, \mathrm{~d}, 8.5$ & $6.71, \mathrm{~d}, 8.5$ \\
3 & $7.55, \mathrm{~d}, 8.5$ & $7.51, \mathrm{~d}, 8.5$ & $7.59, \mathrm{~d}, 8.5$ & $7.41, \mathrm{~d}, 8.5$ \\
5 & $7.22, \mathrm{~s}$ & $7.26, \mathrm{~s}$ & $7.22, \mathrm{~s}$ & $7.25, \mathrm{~s}$ \\
$14 \mathrm{a}$ & $3.35, \mathrm{brd}, 14.0$ & $3.18, \mathrm{dd}, 14.0,5.0$ & $3.14, \mathrm{brd}, 14.0$ & $3.34, \mathrm{dd}, 14.0,2.5$ \\
$14 \mathrm{~b}$ & $2.76, \mathrm{dd}, 14.0,10.5$ & $2.97, \mathrm{dd}, 14.0,8.5$ & $2.72, \mathrm{dd}, 14.0,10.0$ & $2.91, \mathrm{dd}, 14.0,10.5$ \\
15 & $3.84, \mathrm{brd}, 10.5$ & $4.39, \mathrm{~m}$ & $3.78, \mathrm{~d}, 10.0$ & $5.17, \mathrm{dd}, 10.5,7.5$ \\
17 & $1.76, \mathrm{~s}$ & $4.84, \mathrm{~s}, 4.91, \mathrm{~s}$ & $1.32, \mathrm{~s}$ & $1.37, \mathrm{~s}$ \\
18 & $1.73, \mathrm{~s}$ & $1.88, \mathrm{~s}$ & $1.28, \mathrm{~s}$ & $1.33, \mathrm{~s}$ \\
$19 \mathrm{a}$ & $4.43, \mathrm{dd}, 10.5,2.5$ & $4.43, \mathrm{dd}, 11.0,2.5$ & $4.43, \mathrm{dd}, 11.0,3.0$ & $4.43, \mathrm{dd}, 10.5,3.0$ \\
$19 \mathrm{~b}$ & $4.35, \mathrm{dd}, 10.5,2.5$ & $4.35, \mathrm{dd}, 11.0,2.5$ & $4.36, \mathrm{dd}, 11.0,3.0$ & $4.35, \mathrm{dd}, 10.5,3.0$ \\
20 & $2.73, \mathrm{brs}$ & $2.73, \mathrm{brd}, 3.0$ & $2.73, \mathrm{brd}, 2.5$ & $2.73, \mathrm{brd}, 2.5$ \\
$22 \mathrm{a}$ & $4.79, \mathrm{~s}$ & $4.80, \mathrm{~s}$ & $4.80, \mathrm{~s}$ & $4.79, \mathrm{~s}$ \\
$22 \mathrm{~b}$ & $4.56, \mathrm{~s}$ & $4.58, \mathrm{~s}$ & $4.57, \mathrm{~s}$ & $4.56, \mathrm{~s}$ \\
23 & $1.84, \mathrm{~s}$ & $1.85, \mathrm{~s}$ & $1.84, \mathrm{~s}$ & $1.86, \mathrm{~s}$ \\
24 & $2.35, \mathrm{~s}$ & $2.35, \mathrm{~s}$ & $2.35, \mathrm{~s}$ & $2.35, \mathrm{~s}$ \\
25 & $5.40, \mathrm{brs}$ & $5.41, \mathrm{brd} 2.5$ & $5.41, \mathrm{brs}$ & $5.40, \mathrm{brd}, 2.5$ \\
$15-\mathrm{OCH} \mathrm{H}_{3}$ & & & $3.48, \mathrm{~s}$ & \\
$16-\mathrm{OCH}$ & & & $3.29, \mathrm{~s}$ & \\
$\mathrm{OAc}$ & & & & $12.62, \mathrm{~s}$ \\
$\mathrm{OH}_{3}-1$ & $12.63, \mathrm{~s}$ & $12.65, \mathrm{~s}$ & $5.05, \mathrm{~d}, 3.5$ & $12.63, \mathrm{~s}$ \\
$\mathrm{OH}^{2} 25$ & $5.0, \mathrm{brs}$ & $5.03, \mathrm{~d}, 4.0$ & & $4.97, \mathrm{~d}, 3.5$ \\
\hline
\end{tabular}

Table 2. ${ }^{13} \mathrm{C}$ NMR spectroscopic data of compounds $\mathbf{1}-\mathbf{4}\left(\delta_{\mathrm{C}}\right.$, mult, $\left.125 \mathrm{MHz}, \mathrm{CDCl}_{3}\right)$.

\begin{tabular}{cccccccccc}
\hline No. & $\mathbf{1}$ & $\mathbf{2}$ & $\mathbf{3}$ & $\mathbf{4}$ & No. & $\mathbf{1}$ & $\mathbf{2}$ & $\mathbf{3}$ & $\mathbf{4}$ \\
\hline 1 & $160.5 \mathrm{~s}$ & $160.4 \mathrm{~s}$ & $160.2 \mathrm{~s}$ & $160.6 \mathrm{~s}$ & 16 & $74.9 \mathrm{~s}$ & $146.8 \mathrm{~s}$ & $76.5 \mathrm{~d}$ & $72.3 \mathrm{~s}$ \\
2 & $110.0 \mathrm{~d}$ & $109.9 \mathrm{~d}$ & $109.9 \mathrm{~d}$ & $109.6 \mathrm{~d}$ & 17 & $28.9 \mathrm{q}$ & $111.4 \mathrm{t}$ & $22.5 \mathrm{q}$ & $26.9 \mathrm{q}$ \\
3 & $138.3 \mathrm{~d}$ & $138.2 \mathrm{~d}$ & $138.2 \mathrm{~d}$ & $137.8 \mathrm{~d}$ & 18 & $27.9 \mathrm{q}$ & $18.0 \mathrm{q}$ & $20.9 \mathrm{q}$ & $25.2 \mathrm{q}$ \\
4 & $115.9 \mathrm{~s}$ & $115.6 \mathrm{~s}$ & $116.8 \mathrm{~s}$ & $115.1 \mathrm{~s}$ & 19 & $64.6 \mathrm{t}$ & $64.6 \mathrm{t}$ & $64.6 \mathrm{t}$ & $64.5 \mathrm{t}$ \\
5 & $119.1 \mathrm{~d}$ & $119.1 \mathrm{~d}$ & $119.1 \mathrm{~d}$ & $119.2 \mathrm{~d}$ & 20 & $44.9 \mathrm{~d}$ & $44.9 \mathrm{~d}$ & $44.9 \mathrm{~d}$ & $44.9 \mathrm{~d}$ \\
6 & $138.5 \mathrm{~s}$ & $138.5 \mathrm{~s}$ & $138.3 \mathrm{~s}$ & $138.5 \mathrm{~s}$ & 21 & $142.5 \mathrm{~s}$ & $142.5 \mathrm{~s}$ & $142.6 \mathrm{~s}$ & $142.6 \mathrm{~s}$ \\
7 & $149.6 \mathrm{~s}$ & $149.5 \mathrm{~s}$ & $149.5 \mathrm{~s}$ & $149.6 \mathrm{~s}$ & 22 & $112.3 \mathrm{t}$ & $112.3 \mathrm{t}$ & $112.3 \mathrm{t}$ & $112.2 \mathrm{t}$ \\
8 & $121.1 \mathrm{~s}$ & $121.1 \mathrm{~s}$ & $121.1 \mathrm{~s}$ & $121.9 \mathrm{~s}$ & 23 & $22.5 \mathrm{q}$ & $22.5 \mathrm{q}$ & $19.3 \mathrm{q}$ & $20.7 \mathrm{q}$ \\
9 & $109.2 \mathrm{~s}$ & $109.2 \mathrm{~s}$ & $109.2 \mathrm{~s}$ & $109.2 \mathrm{~s}$ & 24 & $17.4 \mathrm{q}$ & $17.4 \mathrm{q}$ & $17.4 \mathrm{q}$ & $17.4 \mathrm{q}$ \\
10 & $153.1 \mathrm{~s}$ & $153.2 \mathrm{~s}$ & $153.0 \mathrm{~s}$ & $153.2 \mathrm{~s}$ & 25 & $63.2 \mathrm{~d}$ & $63.2 \mathrm{~d}$ & $63.2 \mathrm{~d}$ & $63.1 \mathrm{~d}$ \\
11 & $152.0 \mathrm{~s}$ & $152.0 \mathrm{~s}$ & $152.1 \mathrm{~s}$ & $152.0 \mathrm{~s}$ & $15-\mathrm{OCH}_{3}$ & & & $29.7 \mathrm{q}$ & \\
12 & $116.9 \mathrm{~s}$ & $116.8 \mathrm{~s}$ & $116.9 \mathrm{~s}$ & $116.9 \mathrm{~s}$ & $16-\mathrm{OCH}_{3}$ & & & $49.3 \mathrm{q}$ & \\
13 & $184.4 \mathrm{~s}$ & $184.4 \mathrm{~s}$ & $184.5 \mathrm{~s}$ & $184.4 \mathrm{~s}$ & $\mathrm{OAc}\left(\mathrm{CO}^{2}\right.$ & & & & $170.3 \mathrm{~s}$ \\
14 & $31.9 \mathrm{t}$ & $35.3 \mathrm{t}$ & $31.2 \mathrm{t}$ & $29.6 \mathrm{t}$ & $\mathrm{OAc}\left(\mathrm{CH}_{3}\right)$ & & & & $20.7 \mathrm{q}$ \\
15 & $78.5 \mathrm{~d}$ & $75.4 \mathrm{~d}$ & $77.6 \mathrm{~s}$ & $78.6 \mathrm{~d}$ & & & & & \\
\hline
\end{tabular}


Figure 5. Key HMBC and COSY correlations of compound 1.

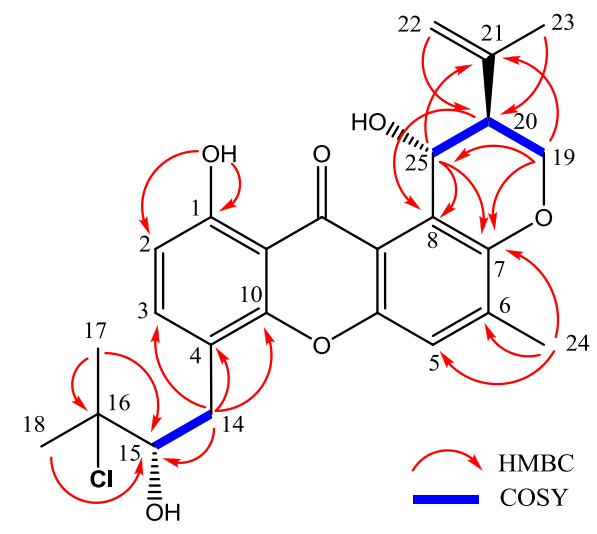

The isotopic ion peaks signals (3:1) in the ESIMS spectrum of $\mathbf{1}$ indicating the presence of a chlorine atom in the molecule. The isopentyl moiety connected to position C-4, which is different from ruguloxanthone $\mathrm{B}(\mathbf{8})$ and taxjixanthone hydrate (6), was deduced as 3-chloro-3-methyl-2-hydroxy butyl moiety, by the HMBC and ${ }^{1} \mathrm{H}-{ }^{1} \mathrm{H}$ COSY correlations showed in Figure 5. The chemical shifts of $\mathrm{H}-14 \mathrm{a}, \mathrm{H}-14 \mathrm{~b} / \mathrm{C}-14$ and $\mathrm{H}-15 / \mathrm{C}-15\left(\delta_{\mathrm{H}} / \delta_{\mathrm{C}} 3.35,2.76 / 31.9\right.$ and $\left.3.84 / 78.5\right)$ also suggest $\mathrm{C}-15-\mathrm{OH}, \mathrm{C}-16-\mathrm{Cl}$ replacement of $\mathbf{1}$, rather than $\mathrm{C}-15-\mathrm{Cl}, \mathrm{C}-16-\mathrm{OH}$ moiety [9].

The configurations at C-20, C-25 of $\mathbf{1}$ are the same as those of ruguloxanthone $\mathrm{B}(\mathbf{8})$, whose absolute configuration has been confirmed by $\mathrm{X}$-ray. The configuration at $\mathrm{C}-15$ is same as taxjixanthone hydrate (6), on the basis of comparison of optical rotation data $\left[-78.1\left(c 0.0031, \mathrm{CHCl}_{3}\right)\right]$ of 1 and [-76.0 ( $c$ $\left.\left.0.23, \mathrm{CHCl}_{3}\right)\right]$ of 6 [11]. Thus, the compound was determined as 16-chlorotajixanthone hydrate, as shown in Figure 5, and named as emerixanthone A (1).

Compound 2 was obtained as yellow crystals and was assigned the molecular formula $\mathrm{C}_{25} \mathrm{H}_{26} \mathrm{O}_{6}$, as deduced from HRESIMS data $\left(\mathrm{m} / \mathrm{z} 423.1804[\mathrm{M}+\mathrm{H}]^{+}\right.$, calcd for 423.1808), indicating 13 degrees of unsaturations. The IR spectrum showed the presence of hydroxyl $3444(\mathrm{OH}), 2954$, and conjugated ketone groups 1724, 1639, 1604, $1573(\mathrm{C}=\mathrm{O}), 1469,1413,1350,1273,1195,1049$, and $1018(\mathrm{C}-\mathrm{O}-\mathrm{C})$ 902, and $864 \mathrm{~cm}^{-1}$. The ${ }^{1} \mathrm{H}$ and ${ }^{13} \mathrm{C}$ NMR spectra of 2 (Tables 1 and 2) were similar to those of $\mathbf{1}$ except for the absence of a 3-chloro-3-methyl-2-hydroxy butyl side chain, which was replaced by a 3-methyl-2-hydroxy-but-3-enyl side chain. The $\mathrm{HMBC}$ spectrum showed the correlations of $\mathrm{H}_{2}-14$ to C-3, C-4, C-10, C-15, and C-16; H-15 to C-16 and C-18; $\mathrm{H}_{3}-17$ to C-15 and C-18, which supported the presence of this side chain. Compound 2 showed a negative specific optical rotation $[-54.3$ (c 0.0065, $\left.\mathrm{CHCl}_{3}\right)$ ], in contrast to the related compound ruguloxanthone $\mathrm{C}$ [+71 (c $\left.\left.0.06 \mathrm{CHCl}_{3}\right)\right]$, which were reported to as an $R$ configuration at $\mathrm{C}-15$ [12]. On the basis of this evidence as well as the comparison of CD spectrum of 1 with 2 (Figure 6), 15S, 20S, 25R configuration of $\mathbf{2}$ was confirmed, as same as that of $\mathbf{1}$. The new prenylxanthone was named as emerixanthone B (2).

Compound 3 was obtained as yellow needle crystals and was assigned the molecular formula $\mathrm{C}_{27} \mathrm{H}_{32} \mathrm{O}_{7}$, as deduced from HRESIMS data $\left(\mathrm{m} / \mathrm{z} 469.2217[\mathrm{M}+\mathrm{H}]^{+}\right.$, calcd for 469.2226), indicating 12 degrees of unsaturations. The IR spectrum showed the presence of hydroxy $3429(\mathrm{OH}), 2920$, and aromatic ketone 1639 and $1573(\mathrm{C}=\mathrm{O}), 1473,1431,1292,1149,1049,1018(\mathrm{C}-\mathrm{O}-\mathrm{C})$, and $856 \mathrm{~cm}^{-1}$. The NMR spectra revealed the same prenylxanthone skeleton of $\mathbf{3}$ as those of $\mathbf{1 , 2}$ and $\mathbf{8}$. The ${ }^{1} \mathrm{H}$ and ${ }^{13} \mathrm{C}$ NMR spectra of $\mathbf{3}$ (Tables 1 and 2) were much similar to those of tajixanthone methonate (10) [11] 
except for the additional methoxy signal $\delta_{\mathrm{H}} 3.48\left(3 \mathrm{H}, \mathrm{s}, \mathrm{OCH}_{3}\right)$ corresponding to $\mathrm{C}-15$. One more methoxy signal $\delta_{\mathrm{H}} 3.29\left(3 \mathrm{H}, \mathrm{s}, \mathrm{OCH}_{3}\right)$ was found to be connected to $\mathrm{C}-16$, as same as that of $\mathbf{1 0}$. Thus, the side chain of $\mathbf{3}$ was deduced as 2, 3-dimethoxy-3-methyl butyl, which is confirmed by the HMBC spectrum. Compound 3 also exhibited negative specific optical rotation [-95.5 (c 0.0018, $\left.\left.\mathrm{CHCl}_{3}\right)\right]$ in the same manner as $\mathbf{1}$. The comparison of CD spectrum of $\mathbf{3}$ with $\mathbf{1}$ and $\mathbf{2}$ (Figure 6) also showed the same configuration of $\mathbf{3}$. This is the third new prenylxanthone,15,16-dimethoxytajixanthone hydrate, named as emerixanthone $\mathrm{C}(\mathbf{3})$.

Figure 6. Circular dichroism spectra of compounds 1-3.

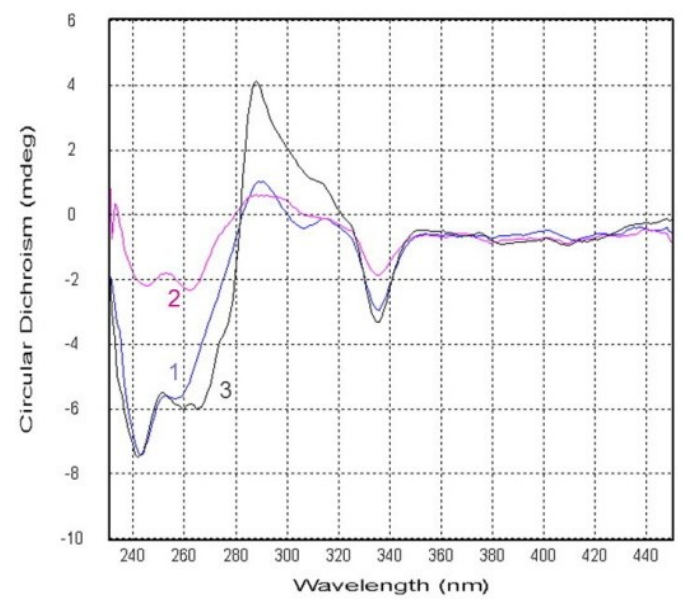

Compound 4 was obtained as yellow needle crystals and was assigned the molecular formula $\mathrm{C}_{27} \mathrm{H}_{30} \mathrm{O}_{8}$, as deduced from HRESIMS data $\left(m / z 483.2015[\mathrm{M}+\mathrm{H}]^{+}\right.$, calcd for 483.2019), indicating 13 degrees of unsaturations. The NMR spectra revealed the same prenylxanthone skeleton of 4 as those of 1-3. The ${ }^{1} \mathrm{H}$ and ${ }^{13} \mathrm{C}$ NMR spectra of 4 (Tables 1 and 2) were much close to those of tajixanthone hydrate (6) [11], except for the additional acetate group $\left(\delta_{\mathrm{C}} 170.3,20.7 ; \delta_{\mathrm{H}} 1.84,3 \mathrm{H}, \mathrm{s}\right)$ connected to $\mathrm{C}-15\left(\delta_{\mathrm{C}} 78.6 ; \delta_{\mathrm{H}} 5.17,1 \mathrm{H}, \mathrm{dd}, J=10.5,3.0 \mathrm{~Hz}\right)$. The multiplicity and coupling constant values for $\mathrm{H}-14 \mathrm{a}, \mathrm{H}-14 \mathrm{~b}$, and $\mathrm{H}-15$ of $\mathbf{4}$ were very similar to those of $\mathbf{3}$ and $\mathbf{6}$, suggesting the same relative stereochemistry for these compounds. The optical rotation data [-93.3 (c 0.009, $\left.\mathrm{CHCl}_{3}\right)$ ] also confirmed the same configuration of $\mathbf{4}$ as $\mathbf{3}$. Compound $\mathbf{4}$ was deduced as taxjixanthone hydrate-15-acetate (4). Tajixanthone hydrate (6) was stable and no change has been found subject to the extraction conditions, and taxjixanthone hydrate-15-formate was also reported as natural product [14]. Accordingly we believe that 4 is a true natural product, named as emerixanthone D (4).

\subsection{Biological Activities of the Isolated Compounds}

The isolated prenylxanthone derivatives 1-10 were evaluated for antibacterial, antifungal, and antitumor activities. Compounds $\mathbf{1}$ and $\mathbf{3}$ showed weak antibacterial activity against all pathogens Escherichia coli (ATCC 29922), Klebsiella pneumonia (ATCC 13883), Staphylococcus aureus (ATCC 29213), Enterococcus faecalis (ATCC 29212), Acineto bacterbaumannii (ATCC 19606), and Aeromonas hydrophila (ATCC 7966). The diameters of inhibition zones of $\mathbf{1}$ and $\mathbf{3}$ against sixpathogens were all 4-6 mm, while that of the positive control ciprofloxacin was about 35-40 mm. Compound 4 also showed mild antifungal activity against all agricultural pathogens Fusarium sp., 
Penicillium sp., Aspergillus niger, Rhizoctonia solani, Fusariumoxy sporium $f$. sp. niveum, Fusariumoxy sporium $f$. sp. cucumeris, diameters of inhibition zones of which were both 3-4 mm. The diameters of inhibition zones of the positive control, carbendazim, were about 40-45 $\mathrm{mm}$. None of them displayed inhibitory activity against ten human tumor cell lines (K562, A549, HL60, Huh-7, MCF-7, H1975, U937, BGC-823, Hela, and Molt-4).

\subsection{Discussion}

Prenylxanthone derivatives have also been found in other Emericella fungi, such as E. rugulosa [12] and E. variecolor (Aspergillus variecolor) [11,13]. The biosynthesis of tajixanthone (9) and related metabolites of $A$. variecolor has been studied by incorporation experiments, and it provided further circumstantial evidence that this group of metabolites was biogenetically related to tajixanthone (9) and shamixanthone (5) [15]. The formation of shamixanthone (5) occurs by cyclodehydration of the dihydroxybenzophenone system present as a two hemiketal forms as arugosis A and B, could be an intermediate in the biosynthesis of tajixanthone, being formed through oxidative ring cleavage of a suitably substituted anthraquinone. Subsequent cyclodehydration and intramolecular 'ene' cyclization of the orthoprenyloxy aldehyde moiety would provide the xanthone nucleus and the substituted dihydropyran ring respectively. From this result, compounds 1-4 were obtained through the tajixanthone biosynthetic pathway under various modification of such as hydroxylation, oxidation, chlorination, acetylation, methylation, and rearrangement (Figure 7).

\section{Experimental Section}

\subsection{General}

Optical rotations were measured with a perkine Elmer 341 polarimeter. Circular dichroism spectra were measured with a Chirascan circular dichroism spectrometer (Applied Photophysics, Ltd., Leatherhead, UK). NMR spectra were obtained on a Bruker AVANCE-500 spectrometer (Bruker, Karlsruhe, Germany) with TMS as internal standard, and chemical shifts were recorded as ä-values. HRESIMS were performed on a Q-Tof Micro mass spectrometer (Waters, Manchester, UK). Silica gel (100-200 and 200-300 mesh), and Sephadex LH-20 for column chromatography were purchased from Qingdao Marine Chemical Group Co. (Qingdao, China), and GE Healthcare (Uppsala, Sweden), respectively.All solvents used were of analytical grade (Tianjin Fuyu Chemical and Industry Factory, Tianjin, China).

\subsection{Fungal Material and Fermentation}

The strain SCSIO 05240 was isolated from a sediment sample (E $\left.120^{\circ} 0.975^{\prime}, \mathrm{N} 19^{\circ} 0.664^{\prime}\right)$ at the depth of $3258 \mathrm{~m}$ collected from an open voyage to the South China Sea in August 2007, and was deposited in the type culture collection of Center for Marine Microbiology, Research Network of Applied Microbiology, South China Sea Institute of Oceanology, CAS, Guangzhou, China. The fungus was identified by sequence analysis of the ITS1-5.8S-ITS2 sequence region and micromorphology as described previously [16]. 
The pure strain SCSIO 05240 colonies were sub-cultured in $100 \mathrm{~mL}$ Erlenmeyer flasks each containing $25 \mathrm{~mL}$ of malt media ( $20 \mathrm{~g} / \mathrm{L}$ of malt extract, $1 \mathrm{~g} / \mathrm{L}$ of peptone, and $30 \mathrm{~g} / \mathrm{L}$ of sea salt). For a large scale culture, $25 \mathrm{~mL}$ of the seed culture was transferred to a $1000 \mathrm{~mL}$ Erlenmeyer flask containing solid rice medium ( $200 \mathrm{~g}$ rice, $200 \mathrm{~mL}$ of water, $3 \%$ sea salt), and incubated at $28^{\circ} \mathrm{C}$ under static stations and daylight. After one month, cultures from 30 flasks were harvested for isolation of compounds with antimicrobial activity.

Figure 7. Proposed biosynthetic pathway of compounds 1-10.

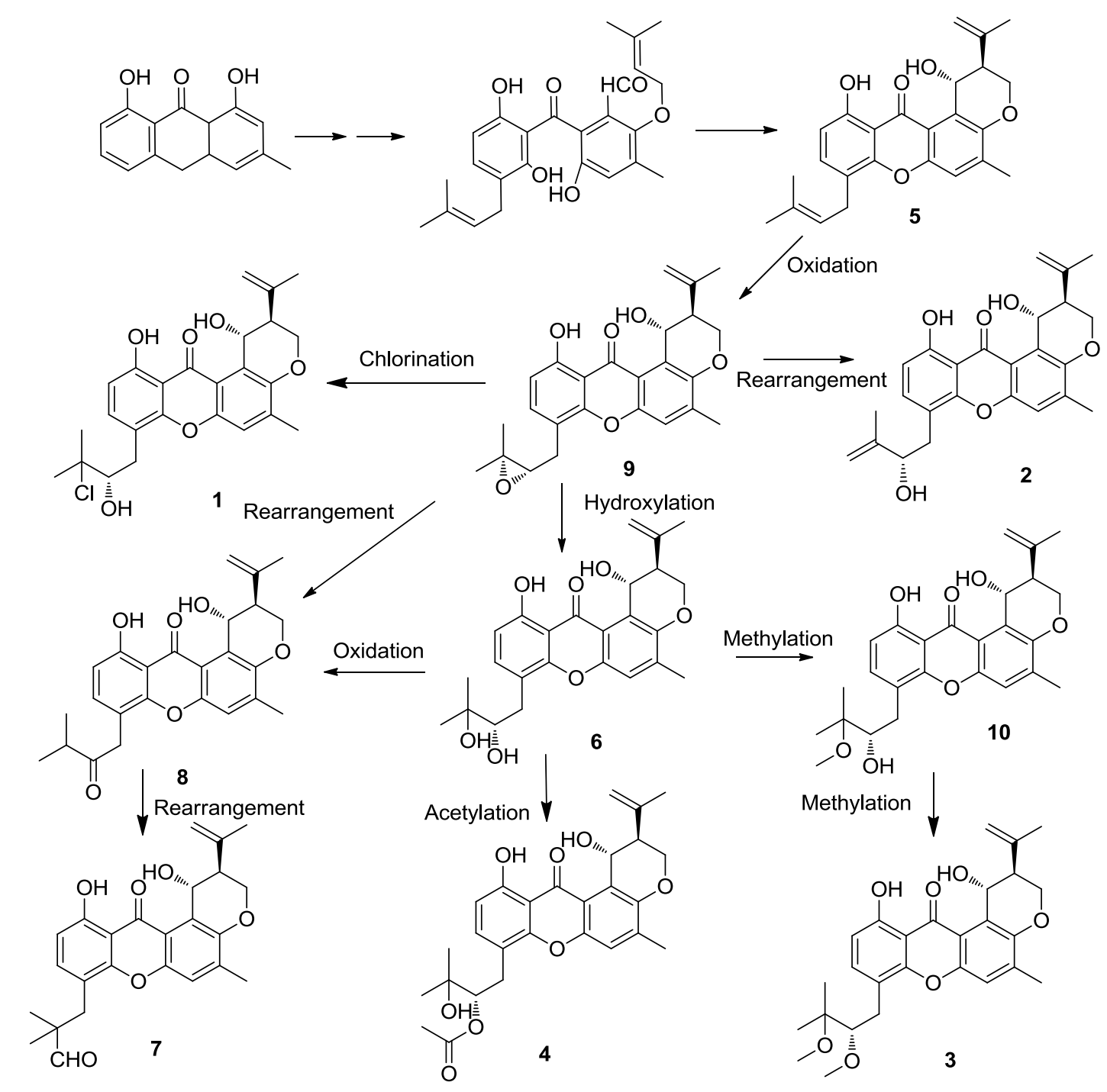

\subsection{Extraction and Isolation}

The culture medium containing the mycelium was cut into small pieces and extracted three times with EtOAc $(3 \times 6 \mathrm{~L})$. The combined EtOAc extract was filtered and evaporated to afford $120 \mathrm{~g}$ of crude extract. The crude EtOAc extract was partitioned between hexanes and $90 \% \mathrm{MeOH}$. The resulting $\mathrm{MeOH}$ fraction (42.5 g) was subjected to silica gel column chromatography (CC) eluted with petroleum ether/EtOAc in linear gradient $(90: 10,80: 20,50: 50,25: 75)$ and followed by $\mathrm{CHCl}_{3} / \mathrm{MeOH}$ in linear gradient $(90: 10,80: 20,70: 30,60: 40,0: 100)$ to obtained 18 fractions (fr.1-18) on the basis of TLC profiles. Fr.8 (280 mg) was subjected to Sephadex LH-20 $\left(\mathrm{CHCl}_{3} / \mathrm{MeOH} 1: 1\right)$ to furnish 
four sub-fractions, designated as fr.8-1 to 8-4. Fr.8-2 (165.2 $\mathrm{mg})$ was further purified by CC on silica gel $\left(\mathrm{CHCl}_{3} / \mathrm{MeOH}, 40: 1\right)$ to give $1(120.4 \mathrm{mg})$ and $5(16.7 \mathrm{mg})$. Fr.6 (240 mg) was purified by Sephadex $\mathrm{LH}-20\left(\mathrm{CHCl}_{3} / \mathrm{MeOH}, 1: 1\right)$ to give four sub-fractions, labeled as fr.6-1 to 6-4). Fr.6-3 (127 mg) was further purified by $\mathrm{CC}$ on silica gel $\left(\mathrm{CHCl}_{3} / \mathrm{MeOH}\right.$, gradient elution 100:1 10:1) to afford $2(13.1 \mathrm{mg})$ and 6 (38.6 mg). Fr.7 $(210 \mathrm{mg})$ was separated by Sephadex LH-20 $\left(\mathrm{CHCl}_{3} / \mathrm{MeOH}\right.$ $1: 1)$ to obtained three fractions termed as fr.7-1 to 7-3. Fr.7-2 $(84.2 \mathrm{mg})$ was further purified by HPLC to give 8 (13.7 mg) and 9 (17.4 mg). Fr.12 (276 mg) was separated by Sephadex LH-20 $\left(\mathrm{CHCl}_{3} / \mathrm{MeOH}\right.$ $1: 1)$ to furnish four sub-fractions named as fr.12-1 to 12-4. Fr.12-1 (22.8 mg) was further purified by HPLC to give 3 (7.5 mg). Fr.12-2 (186 mg) was further purified by $\mathrm{CC}$ on silica gel $\left(\mathrm{CHCl}_{3} / \mathrm{MeOH}\right.$, gradient elution 100:1 10:1) to give $10(108.2 \mathrm{mg})$ and $7(12.3 \mathrm{mg})$. Fr.14 (1 g) was subjected to Sephadex $\mathrm{LH}-20\left(\mathrm{CHCl}_{3} / \mathrm{MeOH} 1: 1\right)$ to obtained four sub-fractions, designated as fr.14-1 to 14-4. Compound 4 (24.4 mg) was obtained by the separation of fr.14-3 on a reversed-phase HPLC eluting with $75 \% \mathrm{MeOH}$.

Emerixanthone A (1): Yellow needle crystals; $[\alpha]_{\mathrm{D}}^{25}-78.1$ (c $\left.0.0031, \mathrm{CHCl}_{3}\right) ; \mathrm{UV}\left(\mathrm{CHCl}_{3}\right)$ $\lambda_{\max }(\log \varepsilon) 395$ (3.39), 298 (3.63), 294 (3.62), 277 (4.21), 248 (4.04), 228 (4.33) nm; IR $v_{\max } 3394$, 2978, 2916, 1639, 1573, 1473, 1431, 1354, 1292, 1242, $1049,1018,856,821 \mathrm{~cm}^{-1} ;{ }^{1} \mathrm{H}$ and ${ }^{13} \mathrm{C}$ NMR data see Tables 1 and 2; HRESIMS $m / z 459.1569[\mathrm{M}+\mathrm{H}]^{+}$(calcd for $\mathrm{C}_{25} \mathrm{H}_{28} \mathrm{ClO}_{6}, 459.1574$ ) (Supplementary Figures S1-S9).

Emerixanthone B (2): Yellow crystals; $[\alpha]_{\mathrm{D}}^{25}-54.3\left(c 0.0065, \mathrm{CHCl}_{3}\right) ; \mathrm{UV}\left(\mathrm{CHCl}_{3}\right) \lambda_{\max }(\log \varepsilon) 397$ (3.45), 300 (3.63), 292 (3.59), 277 (4.14), 242 (3.88), 228 (3.67) nm; IR $v_{\max }$ 3444, 2954, 1724, 1639, 1604, 1573, 1469, 1413, 1350, 1273, 1195, 1049, 1018, 902, $864 \mathrm{~cm}^{-1} ;{ }^{1} \mathrm{H}$ and ${ }^{13} \mathrm{C}$ NMR data see Tables 1 and 2; HRESIMS $m / z$ 423.1804 $[\mathrm{M}+\mathrm{H}]^{+}$(calcd for $\mathrm{C}_{25} \mathrm{H}_{27} \mathrm{O}_{6}, 423.1808$ ) (Supplementary Figures S10-S15).

Emerixanthone C (3): Yellow needle crystals; $[\alpha]_{\mathrm{D}}^{25}-95.5\left(c 0.0018 \mathrm{CHCl}_{3}\right) ; \mathrm{UV}\left(\mathrm{CHCl}_{3}\right) \lambda_{\max }(\log \varepsilon)$ 398 (3.21), 300 (3.41), 291 (3.34), 277 (4.0), 249 (3.16), 228 (4.21) nm; IR $v_{\max }$ 3429, 2920, 1639, 1573, 1473, 1431, 1292, 1149, 1049, 1018, $856 \mathrm{~cm}^{-1} ;{ }^{1} \mathrm{H}$ and ${ }^{13} \mathrm{C}$ NMR data see Tables 1 and 2; HRESIMS $m / z$ 469.2217 [M+ H] ${ }^{+}$(calcd for $\mathrm{C}_{27} \mathrm{H}_{33} \mathrm{O}_{7}$, 469.2226) (Supplementary Figures S16-S20).

Emerixanthone D (4): Yellow needle crystals; $[\alpha]_{\mathrm{D}}^{25}-93.3$ (c $\left.0.009 \mathrm{CHCl}_{3}\right)$; $\mathrm{UV}\left(\mathrm{CHCl}_{3}\right)$ $\lambda_{\max }(\log \varepsilon) 396$ (3,61), 299 (3.79), 291 (3.74), 277 (4.32), 249 (3.84), 242 (3.96), 228 (3.29) nm; IR $v_{\max } 3479,2924,1708,1643,1573,1469,1242,1114,1033,987,856 \mathrm{~cm}^{-1} ;{ }^{1} \mathrm{H}$ and ${ }^{13} \mathrm{C}$ NMR data see Tables 1 and 2; HRESIMS $m / z$ 483.2015 [M + H] ${ }^{+}$(calcd for $\mathrm{C}_{27} \mathrm{H}_{31} \mathrm{O}_{8}, 483.2014$ ) (Supplementary Figures S21-S28).

\subsection{X-ray Crystallographic Analysis of Ruguloxanthone B (8)}

Yellow crystal of $\mathrm{C}_{25} \mathrm{H}_{26} \mathrm{O}_{6}, M=422.46$. Unit cell dimensions $a=12.7104(9) \AA, b=28.731(3) \AA$, $c=6.0033(3) \AA, V=2192.3(3) \AA^{3}, Z=4$; crystal size $0.40 \times 0.09 \times 0.05 \mathrm{~mm}^{3}$. A total of 3769 unique reflections $\left(\theta=66.02^{\circ}-99.00^{\circ}\right)$ were collected using graphite monochromated $\mathrm{Cu} K \alpha$ radiation $(\lambda=0.71073 \AA)$ on a Bruker Smart 1000 CCD diffractometer at $150(2) \mathrm{K}$. Absorption corrections were done by semi-empirical from equivalents. The structure was solved by direct methods (SHELXS-97) and refined with Full-matrix least-squares on 3769 data, 0 restraints and 287 variable parameters. 
Final $R$ indicates $R_{1}=0.0946, w R_{2}=0.1414[I>2 \sigma(\mathrm{I})]$. Crystallographic data for 8 has been deposited in the Cambridge Crystallographic Data Centre with the deposition number 992736. Copies of the data can be obtained, free of charge, on application to the director, CCDC, 12 Union Road, Cambridge CB21EZ, UK (Fax: +44-(0)1223-336033, or E-Mail: deposit@ccdc.cam.ac.uk).

\subsection{Cytotoxic, Antibacterial, and Antifungal Assay}

The cytotoxic activities against ten human tumor cell lines, K562, A549, HL60, Huh-7, MCF-7, H1975, U937, BGC-823, Hela, and Molt-4, were determined according to previously reported methods [17]. Antibacterial and antifungal assay against Escherichia coli (ATCC 29922), Klebsiella pneumonia (ATCC 13883), Staphylococcus aureus (ATCC 29213), Enterococcus faecalis (ATCC 29212), Acinetobacter baumannii (ATCC 19606), Aeromonas hydrophila (ATCC 7966) and pathogens Fusarium sp., Penicillium sp., Aspergillus niger, Rhizoctonia solani, Fusariumoxy sporium f. sp. niveum, Fusariumoxy sporium $f$. sp. Cucumeris were carried out using the filter paper discagar diffusion method [18]. 25 Microliters $(50 \mu \mathrm{g} / \mathrm{mL})$ of the compound were impregnated on sterile filter paper discs (6 $\mathrm{mm}$ diameter). Ciprofloxacin and carbendazim were used as a positive control.

\section{Conclusions}

In summary, four new prenylxanthones (1-4), including a chlorine-containing prenylxanthone, and six known analogues (5-10), were isolated from the deep-sea sediment derived fungus Emericella sp. SCSIO 05240. Their structures were determined on the interpretation of the NMR, MS, X-ray, OR and $\mathrm{CD}$ analysis. Compounds 1, 3 and 4 exhibited weak antibacterial or antifungal activities.

\section{Acknowledgments}

This work was supported by grants from the National High Technology Research and Development Program of China (863 Program, 2012AA092104), National Key Basic Research Program of China (973)'s project (2010CB833800 and 2011CB915503), Postdoctoral Science Foundation of China (2012M511848), National Natural Science Foundation of China (31270402, 21172230, 41376162 and 21302198), and Innovative Development and Regional Demonstration Project of Guangdong Marine Economy (GD2012-D01-001). We thank Li X.R., Xiao Z.H. and Sun A.J. for providing help for NMR and Mass spectrum of these compounds, and Zhang L.P. for his assistance in scanning electron microscopy experiments.

\section{Author Contributions}

Conceived and designed the experiments: Y.L. Performed the experiments: M.F., X.Z., X.L., X.T., W.A., J.W., S.L., and J.L. Analyzed the data: M.F., X.Z., B.Y., and X.Y. Wrote the paper: M.F., X.Z.

\section{Conflicts of Interest}

The authors declare no conflict of interest. 


\section{References}

1. Pockrandt, D.; Ludwig, L.; Fan, A.; Konig, G.M.; Li, S.M. New insights into the biosynthesis of prenylated xanthones: Xptb from Aspergillus nidulans catalyses an O-prenylation of xanthones. ChemBioChem 2012, 13, 2764-2771.

2. Sousa, M.E.; Pinto, M.M.M. Synthesis of xanthones: An overview. Curr. Med. Chem. 2005, 12, 2447-2479.

3. El-Seedi, H.R.; El-Ghorab, D.M.H.; El-Barbary, M.A.; Zayed, M.F.; Goransson, U.; Larsson, S.; Verpoorte, R. Naturally occurring xanthones; latest investigations: Isolation, structure elucidation and chemosystematic significance. Curr. Med. Chem. 2009, 16, 2581-2626.

4. Pinto, M.M.M.; Castanheiro, R.A.P. Synthesis of prenylated xanthones: An overview. Curr. Org. Chem. 2009, 13, 1215-1240.

5. Pinto, M.M.M.; Sousa, M.E.; Nascimento, M.S.J. Xanthone derivatives: New insights in biological activities. Curr. Med. Chem. 2005, 12, 2517-2538.

6. Castanheiro, R.A.P.; Silva, A.M.S.; Campos, N.A.N.; Nascimento, M.S.J.; Pinto, M.M.M. Antitumor activity of some prenylated xanthones. Pharmaceuticals 2009, 2, 33-43.

7. Blunt, J.W.; Copp, B.R.; Keyzers, R.A.; Munro, M.H.G.; Prinsep, M.R. Marine natural products. Nat. Prod. Rep. 2014, 31, 160-258.

8. Blunt, J.W.; Copp, B.R.; Munro, M.H.G.; Northcote, P.T.; Prinsep, M.R. Marine natural products. Nat. Prod. Rep. 2011, 28, 196-268.

9. Figueroa, M.; Gonzalez Mdel, C.; Rodriguez-Sotres, R.; Sosa-Peinado, A.; Gonzalez-Andrade, M.; Cerda-Garcia-Rojas, C.M.; Mata, R. Calmodulin inhibitors from the fungus Emericella sp. Bioorg. Med. Chem. 2009, 17, 2167-2174.

10. Kralj, A.; Kehraus, S.; Krick, A.; Eguereva, E.; Kelter, G.; Maurer, M.; Wortmann, A.; Fiebig, H.H.; Konig, G.M. Arugosins G and H: Prenylated polyketides from the marine-derived fungus Emericella nidulans var. acristata. J. Nat. Prod. 2006, 69, 995-1000.

11. Pornpakakul, S.; Liangsakul, J.; Ngamrojanavanich, N.; Roengsumran, S.; Sihanonth, P.; Piapukiew, J.; Sangvichien, E.; Puthong, S.; Petsom, A. Cytotoxic activity of four xanthones from Emericella variecolor, an endophytic fungus isolated from Croton oblongifolius. Arch. Pharm. Res. 2006, 29, 140-144.

12. Moosophon, P.; Kanokmedhakul, S.; Kanokmedhakul, K.; Soytong, K. Prenylxanthones and a bicyclo[3.3.1]nona-2,6-diene derivative from the fungus Emericella rugulosa. J. Nat. Prod. 2009, $72,1442-1446$.

13. Chexal, K.K.; Fouweath, C; Holker, J.S.E.; Simpson, T.J.; Young, K. Biosynthesis of fungal metabolites. 3. Structure of shamixanthone and tajixanthone, metabolites of Aspergillus variecolor. J. Chem. Soc. Perkin Trans. 1974, 1, 1584-1593.

14. Malmstrom, J.; Christophersen, C.; Barrero, A.F.; Oltra, J.E.; Justicia, J.; Rosales, A. Bioactive metabolites from a marine-derived strain of the fungus Emericella variecolor. J. Nat. Prod. 2002, 65, 364-367.

15. Ahmed, S.A.; Bardshiri, E.; Mcintyre, C.R.; Simpson, T.J. Biosynthetic studies on tajixanthone and shamixanthone, polyketide hemiterpenoid metabolites of Aspergillus variecolor. Aust. J. Chem.1992, 45, 249-274. 
16. Lin, X.; Zhou, X.; Wang, F.; Liu, K.; Yang, B.; Yang, X.; Peng, Y.; Liu, J.; Ren, Z.; Liu, Y. A new cytotoxic sesquiterpene quinone produced by Penicillium sp. F00120 isolated from a deep sea sediment sample. Mar. Drugs 2012, 10, 106-115.

17. Fang, W.; Lin, X.; Zhou, X.; Wan, J.; Lu, X.; Yang, B.; Ai, W.; Lin, J.; Zhang, T.; Tu, Z.; Liu, Y. Cytotoxic and antiviral nitrobenzoyl sesquiterpenoids from the marine-derived fungus Aspergillus ochraceus Jcma1F17. MedChemComm 2014, doi:10.1039/C3MD00371J.

18. Zeng, Y.-B.; Wang, H.; Zuo, W.-J.; Zheng, B.; Yang, T.; Dai, H.-F.; Mei, W.-L. A fatty acid glycoside from a marine-derived fungus isolated from mangrove plant Scyphiphora hydrophyllacea. Mar. Drugs 2012, 10, 598-603.

(C) 2014 by the authors; licensee MDPI, Basel, Switzerland. This article is an open access article distributed under the terms and conditions of the Creative Commons Attribution license (http://creativecommons.org/licenses/by/3.0/). 